\title{
Efeito do Lactobacillus buchneri na fermentação, estabilidade aeróbia e no valor nutritivo de silagem de cana-de-açúcar ${ }^{1}$
}

\section{Clayton Quirino Mendes², Ivanete Susin ${ }^{3}$, Luiz Gustavo Nussio ${ }^{3}$, Alexandre Vaz Pires ${ }^{3}$, Gustavo Henrique Rodrigues ${ }^{2}$, Fumi Shibata Urano ${ }^{2}$}

\author{
${ }^{1}$ Projeto parcialmente financiado pela FAPESP. \\ 2 Doutorando em Ciência Animal e Pastagens - ESALO/USP - Piracicaba, SP. \\ ${ }^{3}$ Departamento de Zootecnia - ESALQ/USP - Piracicaba, SP. Pesquisador do CNPq.
}

RESUMO - Dois experimentos foram realizados para avaliar o valor nutritivo, a estabilidade aeróbia de silagens de cana-de-açúcar e a digestibilidade aparente de rações contendo essas silagens. No experimento 1, a cana-de-açúcar foi ensilada sem aditivo ou inoculada com cepas NCIMB 40788 do Lactobacillus buchneri (5 x $10^{4}$ ufc/g de matéria verde). Amostras das silagens foram analisadas e comparadas à cana-de-açúcar in natura para avaliação da estabilidade aeróbia, considerando os dados de temperatura, pH e perdas de MS das silagens. No experimento 2, utilizaram-se 12 cordeiros distribuídos em blocos completos casualizados e mantidos em gaiolas para ensaio de metabolismo recebendo rações contendo cana-de-açúcar in natura, silagem de cana-de-açúcar sem aditivo ou silagem de cana-de-açúcar tratada com Lactobacillus buchneri. Os teores de matéria seca, carboidratos solúveis e ácido acético foram maiores na silagem com aditivo. O teor de etanol não diferiu entre as silagens. A silagem tratada com aditivo apresentou menor perda de matéria seca e manutenção do $\mathrm{pH}$ durante o período de avaliação em aerobiose. A digestibilidade aparente de fibra em detergente neutro, fibra em detergente ácido e hemicelulose foram maiores nas rações contendo silagem de cana-de-açúcar.

Palavras-chave: ácido acético, bactérias heterofermentativas, composição química, digestibilidade aparente, etanol

\section{Effect of Lactobacillus buchneri on fermentation, aerobic stability, and nutritive value of sugar cane silage}

\begin{abstract}
Two trials were performed to evaluate the nutritive value and aerobic stability of sugar cane silage, as well as apparent digestibility of diets containing these silages. In trial 1, sugar cane was ensiled without additive or inoculated with strains NCIMB 40788 of Lactobacillus buchneri (5 x $10^{4} \mathrm{cfu} / \mathrm{g}$ wet basis). Silages were sampled, analyzed, and compared with fresh sugar cane. Aerobic stability was evaluated by controlling the temperature, $\mathrm{pH}$, and dry matter losses of the silages. In trial 2, twelve lambs were assigned to a complete randomized block design and placed in metabolism crates and fed with diets composed by fresh sugar cane, sugar cane silage without additive, or sugar cane silage treated with Lactobacillus buchneri. Dry matter, soluble carbohydrates, and acetic acid concentrations were higher for silage treated with Lactobacillus buchneri when compared with silage without additive. There was no difference on ethanol levels between silages. Sugar cane silage treated with Lactobacillus buchneri showed lower dry matter losses, unchanged $\mathrm{pH}$, and greater aerobic stability. Neutral detergent fiber, acid detergent fiber, and hemicellulose apparent digestibility were higher for sugar cane silage treatments.
\end{abstract}

Key Words: acetic acid, apparent digestibility, chemical composition, ethanol, heterofermentative bacteria

\section{Introdução}

Atualmente, a conservação de cana-de-açúcar na forma de silagem tem despertado o interesse de pesquisadores e produtores, sobretudo em virtude dos benefícios em logística e operacionalidade desta técnica.

De acordo com Pedroso et al. (2005), a maior limitação na ensilagem de cana-de-açúcar consiste na elevada produção de etanol. Em razão do alto teor de carboidratos solúveis, o material ensilado apresenta rápida proliferação de leveduras, uma vez que esses microrganismos, em anaerobiose, fermentam os carboidratos, produzindo etanol. Considerando as peculiaridades da ensilagem de cana-de-açúcar, Nussio et al. (2003) descreveram sobre a necessidade de processos específicos para o adequado controle da população e da atividade de leveduras e que não prejudiquem a qualidade da silagem. Adicionalmente, Siqueira et al. (2007) afirmaram que a ensilagem de cana- 
de-açúcar requer a inclusão de aditivo eficiente no controle das perdas quantitativas durante a fermentação e exposição aeróbia.

Aditivos químicos e inoculantes microbianos têm sido utilizados no intuito de melhorar o padrão de fermentação e a qualidade das silagens. Entre os aditivos microbianos utilizados, as bactérias heterofermentativas Lactobacillus buchneri têm se mostrado capazes de reduzir a população de leveduras e aumentar a estabilidade aeróbia de silagens de milho e de gramíneas de clima temperado (Ranjit, 2000; Taylor, 2002). Segundo Kleinschmit \& Kung Jr. (2006), a inoculação de silagens de milho, sorgo, trigo, cevada e gramíneas com Lactobacillus buchneri reduziu a concentração de ácido lático e aumentou a concentração do ácido acético e a estabilidade aeróbia destas silagens por ter inibido o crescimento de leveduras.

Entretanto, estudos para avaliação da estabilidade aeróbia e do efeito desses microrganismos como aditivo na ensilagem de forrageiras tropicais são escassos. Do mesmo modo, são poucos os trabalhos disponíveis na literatura para avaliação da digestibilidade in vivo de dietas contendo silagens de cana-de-açúcar. De acordo com Harrison et al. (1989), diversos autores afirmam que a inoculação de forragens pode melhorar a digestibilidade da silagem, entretanto, os resultados são bastante controversos.

Este estudo foi realizado com os objetivos de avaliar os efeitos da fermentação no valor nutritivo e a capacidade do Lactobacillus buchneri em melhorar a estabilidade aeróbia de cana-de-açúcar conservada na forma de silagem e determinar a digestibilidade aparente de rações contendo silagem de cana-de-açúcar.

\section{Material e Métodos}

No experimento 1 , as silagens avaliadas foram produzidas com a variedade industrial de cana-de-açúcar RB855536, colhida mecanicamente com colhedeira de forragem tracionada por trator, regulada para corte com tamanho médio de partículas de 5 a $10 \mathrm{~mm}$. O ponto ideal de maturação para colheita da cana foi determinado utilizando-se refratômetro de campo, cujo valor médio determinado foi de $21,3^{\circ}$ brix

As silagens experimentais foram confeccionadas em silos tubulares revestidos de lona plástica do tipo bag (Pacifilbag), com diâmetro de 2,7 m e comprimento suficiente para armazenar 40 toneladas de forragem. A cana-de-açúcar foi ensilada sem aditivo ou com inoculante microbiano contendo bactérias heteroláticas Lactobacillus buchneri (cepa NCIMB 40788) na dose de $5 \times 10^{4} \mathrm{ufc} / \mathrm{g}$ de massa verde de forragem, constituindo os tratamentos silagem sem aditivo e silagem contendo Lactobacillus buchneri, respectivamente.

Durante o processo de confecção das silagens, a canade-açúcar in natura foi amostrada dez vezes, de modo que o material de cada amostra foi colhido em cinco pontos diferentes do monte visando obter boa representatividade do material antes da ensilagem. Foram retiradas duas amostras, uma de $500 \mathrm{~g}$ e outra de $100 \mathrm{~g}$, as quais foram imediatamente congeladas para determinação da composição químicobromatológica e confecção do extrato aquoso, respectivamente. As amostras foram analisadas do mesmo modo que as silagens, possibilitando comparar o material antes a após a ensilagem.

Durante o ensaio de desempenho animal (Mendes et al., 2008), amostras das silagens foram coletadas durante dez semanas e conservadas a $-10^{\circ} \mathrm{C}$ para análises posteriores. Uma quantidade de $10 \mathrm{~kg}$ do material ensilado foi retirada do silo e homogeneizada, colhendo-se uma amostra de 500 g para determinação do teor de matéria seca e da composição química e outra de aproximadamente $100 \mathrm{~g}$ para obtenção do extrato aquoso.

As amostras foram descongeladas e acondicionadas em sacos de papel, pesadas e mantidas em estufa de ventilação forçada com temperatura de $55^{\circ} \mathrm{C}$ por 72 horas. Em seguida, foram moídas em moinho tipo Willey com peneira de malha de $1 \mathrm{~mm}$ e analisadas quanto aos teores de matéria seca (MS), proteína bruta (PB), fibra em detergente neutro (FDN), utilizando amilase e sulfito de sódio, e fibra em detergente ácido (FDA), conforme descrito por Campos et al. (2004). A hemicelulose foi obtida pela diferença entre os teores de FDN e de FDA determinados.

O extrato aquoso das amostras de silagem e da canade-açúcar in natura foi obtido de acordo com método descrito por Kung Jr. (1996). Uma alíquota de 25 g de amostra úmida foi processada com $225 \mathrm{~mL}$ de água deionizada em liquidificador industrial durante um minuto. Em seguida, o material foi filtrado, acidificado com ácido sulfúrico $50 \%$ e centrifugado. O extrato obtido foi congelado a $-5^{\circ} \mathrm{C}$ para posterior análise dos teores de ácido acético, carboidratos solúveis (CHOS) e etanol.

As determinações dos teores de carboidratos solúveis foram realizadas por espectrofotometria utilizando-se filtro para absorbância de 490 nm (espectrofotômetro Jenway6405 UV/VIS ${ }^{\circledR}$ ) pelo método descrito por Dubois et al. (1956). O teor de etanol foi determinado por meio de leitura direta em autoanalisador YSI 2700 Select (Biochemistry Analyser, Yellow Spring, Oh, USA), provido de membrana 
com enzima imobilizada. Para determinação do teor de ácido acético, as amostras foram centrifugadas a $15.000 \mathrm{~g}\left(4^{\circ} \mathrm{C}\right)$, durante 50 minutos, e analisadas de acordo com procedimento descrito por Palmquist \& Conrad (1971) em cromatógrafo líquido-gasoso (CLG Hewelett Packard ${ }^{\circledR} 5890$ series II) equipado com integrador e injetor automático. O gás de arraste e os comburentes foram nitrogênio, hidrogênio e oxigênio, nas vazões de 20 , 30 e $40 \mathrm{~mL} / \mathrm{min}$, respectivamente. As temperaturas do injetor, do detector e da coluna foram de 150,190 e $115^{\circ} \mathrm{C}$, respectivamente.

A estabilidade aeróbia das silagens, expressa em horas, foi avaliada pelo controle da temperatura do material exposto ao ar durante 10 dias, segundo metodologia proposta por Kung Jr. (2000). O início da deterioração correspondeu ao momento quando a temperatura das silagens atingiu $2^{\circ} \mathrm{C}$ acima da temperatura ambiente. Amostras em triplicata, de aproximadamente $4 \mathrm{~kg}$ das silagens de cada tratamento, foram colocadas sem compactação em baldes de plástico sem tampa, os quais foram mantidos em ambiente protegido e em temperatura ambiente. A temperatura da silagem foi medida três vezes ao dia (às 8,12 e 20 h) por meio de termômetros posicionados no centro geométrico da massa de forragem de cada balde. A temperatura ambiente, tomada como referência, foi registrada com uso de termômetro localizado no mesmo ambiente em que se encontravam os baldes. Os baldes foram pesados depois de cada tomada de temperatura e amostras de forragem de cada balde foram colhidas e congeladas para posterior determinação do $\mathrm{pH}$.

No experimento para avaliação da digestibilidade, foram utilizados 12 ovinos da raça Santa Inês, com 8 meses de idade e peso médio inicial de 41,6 kg. Os animais foram alojados individualmente em gaiolas metálicas para ensaios de metabolismo, com dimensões de 1,30 x 0,55 m, providas de cocho, bebedouro e sistema para coleta de fezes e urina separadamente.

As rações experimentais (Tabela 1), contendo $50 \%$ de volumoso e $50 \%$ de concentrado, diferiram entre si quanto ao tipo do volumoso utilizado: cana-de-açúcar in natura, silagem de cana-de-açúcar sem aditivo e silagem de cana-de-açúcar aditivada com L. buchneri (5 x $10^{4} \mathrm{ufc} / \mathrm{g} \mathrm{MV}$ ). As rações foram formuladas para atender às exigências de cordeiros com potencial de crescimento moderado, de acordo com o NRC (1985).

As rações foram fornecidas uma vez ao dia, de modo que a silagem e o concentrado foram pesados separadamente em balança eletrônica e misturados manualmente nos cochos. As sobras de alimento de cada baia foram quantificadas diariamente, possibilitando o cálculo do consumo e o ajuste da quantidade de alimento a ser fornecida em cada dia. Como critério na quantificação do alimento, considerou-se sobra de aproximadamente $15 \%$ da oferta, para garantir o consumo ad libitum da ração.

O período experimental teve duração de dez dias: seis de adaptação dos animais às instalações e quatro para coleta dos dados e das amostras. Os dados de consumo de matéria seca por animal por dia foram obtidos pela diferença entre a quantidade de alimento fornecida e a recusada. Foram colhidas amostras dos concentrados, dos volumosos e das sobras nos quatro dias de coleta.

Diariamente, as fezes foram totalmente pesadas e amostras de $10 \%$ do total foram congeladas a $-10^{\circ} \mathrm{C}$. As amostras do alimento oferecido, das sobras e das fezes foram secas em estufa de ventilação forçada a $55^{\circ} \mathrm{C}$ por 72 horas, trituradas em moinho tipo Wiley com peneira com crivos de $2 \mathrm{~mm}$ e posteriormente foram moídas em peneira com crivos de $1 \mathrm{~mm}$ para análises posteriores, realizadas conforme procedimento adotado no experimento de desempenho (Mendes et al., 2008).

A estabilidade aeróbia das silagens foi avaliada utilizando-se o delineamento inteiramente casualizado, com dois tratamentos (silagem de cana e silagem de cana tratada com Lactobacillus buchneri) e quatro repetições. O delineamento experimental utilizado na avaliação da digestibilidade dos nutrientes foi o de blocos completos casualizados (quatro blocos e quatro repetições), sendo que os blocos foram definidos de acordo com a idade e o peso dos animais no início do experimento.

Tabela 1 - Composição das rações experimentais (\% MS)

\begin{tabular}{|c|c|c|c|}
\hline & $\begin{array}{l}\text { Cana-de- } \\
\text { açúcar } \\
\text { in natura }\end{array}$ & $\begin{array}{c}\text { Silagem de } \\
\text { cana } \\
\text { sem aditivo }\end{array}$ & $\begin{array}{c}\text { Silagem de } \\
\text { cana contendo } \\
\text { Lactobacillus } \\
\text { buchneri }\end{array}$ \\
\hline $\begin{array}{l}\text { Cana-de-açúcar } \\
\text { in natura }\end{array}$ & 50,0 & - & - \\
\hline Silagem de cana-de-açúcar & - & 50,0 & 50,0 \\
\hline Milho moído & 9,8 & 9,8 & 9,8 \\
\hline Farelo de soja & 28,2 & 28,2 & 28,2 \\
\hline Polpa cítrica moída & 9,7 & 9,7 & 9,7 \\
\hline Uréia & 0,4 & 0,4 & 0,4 \\
\hline Mistura mineral ${ }^{1}$ & 1,9 & 1,9 & 1,9 \\
\hline \multicolumn{4}{|l|}{ Composição química } \\
\hline Matéria seca & 58,9 & 55,4 & 58,3 \\
\hline Proteína bruta & 16,4 & 17,0 & 17,1 \\
\hline Matéria orgânica & 91,1 & 90,4 & 90,0 \\
\hline $\begin{array}{l}\text { Fibra em detergente } \\
\text { neutro }\end{array}$ & 35,0 & 41,8 & 45,3 \\
\hline $\begin{array}{l}\text { Fibra em detergente } \\
\text { ácido }\end{array}$ & 25,8 & 32,7 & 32,2 \\
\hline
\end{tabular}


Os dados foram analisados pelo procedimento GLM do pacote estatístico SAS (1999). As médias das tabelas foram obtidas pelo comando LSMEANS aplicando-se o teste Tukey $(\mathrm{P}<0,05)$ para as variáveis que apresentaram respostas significativas.

\section{Resultados e Discussão}

Os resultados encontrados na análise da composição bromatológica (Tabela 2) da cana-de-açúcar in natura foram próximos aos descritos na literatura. Os teores de MS e PB da cana-de-açúcar in natura foram de 28,1 e 4,1\%, respectivamente, e os de FDN, FDA e hemicelulose, de 49,9; 28,9 e 21,0\%, respectivamente. Freitas et al. (2006) avaliaram a composição química da cana-de-açúcar e observaram valor médio de $28,6 \%$ de MS. Pedroso et al. (2005) realizaram estudos com cana-de-açúcar com aproximadamente 12 meses de idade e observaram valores de 49,6; 32,5 e 17,1\% para os teores de FDN, FDA ehemicelulose, do mesmo modo que, em análises feitas por Azevêdo et al. (2003) na variedade RB 855536, a mesma utilizada neste estudo, foram observados valores de 27,3\% de MS, 51,5\% de FDN, 26,2\% de FDA e 25,4\% de hemicelulose. Adicionalmente, Silva et al. (2008) verificaram para cana-de-açúcar fresca valores de 36,2; 57,7 e 34,5\% para MS, FDN e FDA, respectivamente.

O teor de carboidratos solúveis (CHOS) na cana-deaçúcar antes da ensilagem foi de 50,1\%, inferior ao observado por Freitas et al. (2006), de 59,9\%, e superior aos $41,1 \%$ encontrado por Silva et al. (2008). Após a ensilagem, houve redução no teor de carboidratos solúveis e aumento nos teores de FDN, FDA, hemicelulose, etanol e ácido acético da cana (Tabela 2), como conseqüência do processo fermentativo característico da cana-de-açúcar, que, segundo Pedroso et al. (2005), resulta em silagens com intensa atividade de leveduras, alto teor de álcool e elevadas perdas de matéria seca.
Os teores de FDN, FDA e hemicelulose aumentaram em comparação ao material original. Entretanto, esses valores foram semelhantes entre as silagens. O teor de MS da silagem de cana-de-açúcar sem aditivo foi menor $(\mathrm{P}<0,01)$ que o da cana-de-açúcar in natura e o da silagem inoculada com Lactobacillus buchneri. Na silagem sem aditivo, observou-se redução de 6,4 pontos percentuais no teor de MS, enquanto na silagem aditivada não houve alteração. Portanto, o inoculante pode ter evitado as perdas decorrentes do processo de ensilagem. Pedroso et al. (2005) observaram redução de 9,0 pontos percentuais no teor de MS da cana-de-açúcar ensilada sem aditivo, o qual passou de 34,5\% para 25,5\% após 180 dias de ensilagem. Esses mesmos autores relataram aumentos nos teores de FDN e FDA, que passaram de 49,6 e 32,5\% para 72,9 e 45,8\% no material com 180 dias de conservação. Dados semelhantes foram observados por Santos et al. (2006), que avaliaram as características da silagem de cana-de-açúcar em duas idades de corte e verificaram valores de 29,3\% de MS, 48,6\% de FDN e 26,2\% de FDA na cana-de-açúcar in natura com 11 meses de idade e 23,6\% de MS, 69,9\% de FDN e 43,05\% de FDA no material ensilado, respectivamente.

Da mesma forma, Freitas et al. (2006) avaliaram a qualidade nutricional da silagem de cana-de-açúcar inoculada com aditivos microbianos e observaram redução no teor de MS e maiores concentrações dos componentes fibrosos. Esses autores observaram em silagem de canade-açúcar sem aditivo 27,7\% de MS, 36,0\% de FDN e 23,5\% de FDA e, ao adicionarem o inoculante microbiano Lactobacillus buchneri, na mesma dose utilizada neste trabalho (5 x $10^{4}$ ufc/g na matéria verde), verificaram valores de 20,7\% de MS, 64,7\% de FDN e 43,3\% de FDA.

Os dados obtidos nesta pesquisa (Tabela 2) confirmam a afirmação feita por Pedroso et al. (2005) de que a maior concentração dos componentes da fibra na MS das silagens é ocasionada pelas perdas de carboidratos solúveis durante a fermentação. Neste trabalho, houve redução de 91,0 e

Tabela 2 - Composição da cana-de-açúcar in natura e das silagens experimentais (\%MS)

\begin{tabular}{|c|c|c|c|c|}
\hline Componente & $\begin{array}{l}\text { Cana-de-açúcar } \\
\text { in natura }\end{array}$ & $\begin{array}{c}\text { Silagam de cana-de-açúcar } \\
\text { sem aditivo }\end{array}$ & $\begin{array}{l}\text { Silagem de cana-de-açúcar } \\
\text { contendo Lactobacillus buchneri }\end{array}$ & $\mathrm{CV}^{1}$ \\
\hline Matéria seca & $28,1 \mathrm{a}$ & $21,7 b$ & $27,6 a$ & 5,53 \\
\hline Fibra em detergente neutro & $49,9 a$ & $62,5 b$ & $69,4 b$ & 5,34 \\
\hline Fibra em detergente ácido & $28,9 a$ & $42,8 b$ & $46,3 b$ & 6,64 \\
\hline Hemicelulose & 21,0 & 19,7 & 23,1 & 5,98 \\
\hline Etanol & $\mathrm{nd}^{2}$ & 3,2 & 2,8 & 22,43 \\
\hline
\end{tabular}

${ }^{1}$ Coeficiente de variação; ${ }^{2}$ Não-determinado.

a,b,c Médias seguidas de letras distintas na mesma linha diferem $(P<0,01)$ pelo teste Tukey. 
89,2\% nos teores de carboidratos solúveis da silagem de cana-de-açúcar sem aditivo e da silagem de cana-deaçúcar com Lactobacillus buchneri, respectivamente. A silagem sem aditivo apresentou a menor concentração de carboidratos solúveis, o que indica fermentação mais intensa, com maior consumo de compostos solúveis. Esses valores são próximos às perdas de $93 \%$ de carboidratos solúveis encontradas por Alli et al. (1982). Adicionalmente, Freitas et al. (2006) ensilaram cana-de-açúcar contendo $59,9 \%$ de carboidratos solúveis e observaram concentrações de 6,4 e 4,8\% desses carboidratos na silagem sem aditivo e naquela aditivada com Lactobacillus buchneri, respectivamente.

Por meio da fermentação alcoólica realizada pelas leveduras, cada mólecula de glicose fermentada produz duas moléculas de etanol, duas de dióxido de carbono e duas de água. O etanol produzido causa grande perda energética da forragem, uma vez que é formado a partir da fermentação da glicose. Neste estudo não houve diferença $(\mathrm{P}>0,05)$ para os teores de etanol encontrados nas silagens. As concentrações obtidas foram de 3,2 e 2,8\% de etanol para as silagens de cana-de-açúcar sem aditivo e com Lactobacillus buchneri, respectivamente. Esses resultados estão de acordo com o esperado para silagens com intensa atividade de leveduras e presença de bactérias heterofermentativas. O teor de etanol observado neste estudo foi similar ao encontrado por Pedroso et al. (2007) para cana-de-açúcar ensilada sem aditivos (3,82\%) e para a silagem com Lactobacillus buchneri (1,95\%).

Driehuis et al. (1999) observaram acúmulo de ácido acético em silagens de milho inoculadas com Lactobacillus buchneri, observação confirmada em diversos trabalhos realizados com silagens de milho, sorgo, trigo, cevada e gramíneas (Kleinschmit \& Kung Jr., 2006). Resultado semelhante ocorreu neste estudo, em que as concentrações de ácido acético foram maiores $(\mathrm{P}<0,01)$ na silagem aditivada (5,7\%), com aumento de $40 \%$ em comparação àquela sem aditivo (4,1\%). O maior teor de ácido acético na silagem sem aditivo pode ter sido ocasionado pela presença de microrganismos heterofermentativos autóctones. Segundo Driehuis et al. (2001), a degradação anaeróbia do ácido lático pode ocorrer em silagens não inoculadas, uma vez que bactérias acidoláticas, principalmente espécies de Lactobacillus buchneri, predominam na microbiota epífita desses materiais.

De acordo com Kleinschmit \& Kung Jr. (2006), o Lactobacillus buchneri é uma bactéria heterolática e que tem sido utilizada como inoculante de silagens para aumentar a estabilidade aeróbia por meio da degradação anaeróbia do ácido lático em ácido acético.
A silagem de cana-de-açúcar aditivada com Lactobacillus buchneri apresentou maior $(\mathrm{P}<0,01)$ estabilidade aeróbia (Tabela 3) em relação à silagem sem aditivo. A temperatura ambiente, tomada como referência, apresentou média de $20,5^{\circ} \mathrm{C}$. Nestas condições, a silagem sem aditivo atingiu temperatura máxima de $37,8^{\circ} \mathrm{C}$ após 96 horas de exposição ao ar, enquanto, na silagem aditivada, a temperatura máxima foi de $22,5^{\circ} \mathrm{C}$ após 120 horas em aerobiose. A silagem de cana-de-açúcar sem aditivo apresentou estabilidade de 56 horas e acúmulo da diferença média entre a temperatura ambiente e a temperatura das silagens nos primeiros cinco dias de exposição ao ar (TA5), de $25^{\circ} \mathrm{C}$, enquanto, na silagem de cana-de-açúcar aditivada, os valores foram de 92 horas e $18,2^{\circ} \mathrm{C}$ para a estabilidade e TA5, respectivamente. A aplicação do inoculante contendo Lactobacillus buchneri aumentou a estabilidade aeróbia da silagem de cana-de-açúcar em $64,0 \%$ e reduziu a TA5 em 27,2\%. Da mesma forma, pesquisando os efeitos de diversos aditivos antifúngicos sobre a fermentação e a estabilidade aeróbia de silagem de milho, Kleinschmit et al. (2005) concluíram que silagens contendo Lactobacillus buchneri apresentam maiores concentrações de ácido acético, menores teores de etanol e ausência de leveduras e permanecem estáveis por 139 horas. Siqueira et al. (2007) avaliaram silagens de cana-de-açúcar tratadas com aditivos químicos e bacterianos e observaram maior estabilidade aeróbia nas silagens com Lactobacillus buchneri (60 horas) em comparação à silagem sem aditivo (32 horas).

Verificou-se efeito do inoculante sobre as perdas de MS e sobre o $\mathrm{pH}$ das silagens durante o período de exposição ao ar (Tabela 3), pois as perdas de MS foram menores na silagem com Lactobacillus buchneri. Os valores encontrados na silagem sem aditivo e contendo Lactobacillus buchneri foram de 11,1 e 7,7\% até o quinto dia de exposição ao ar. A partir do quinto dia, as perdas de matéria seca aumentaram em ambas as silagens e mantiveram-se inferiores na silagem aditivada. Pedroso et al. (2007) observaram que a inoculação de silagem de cana-de-açúcar com Lactobacillus buchneri reduziu em 56\% a perda total de matéria seca e concluíram que a redução das perdas indica controle no desenvolvimento de leveduras na silagem inoculada.

Ranjit \& Kung Jr. (2000) avaliaram silagens de milho aditivadas com Lactobacillus buchneri e constataram que as silagens apresentaram padrão fermentativo satisfatório e se mantiveram estáveis quando expostas ao ar. Segundo os autores, esse resultado foi ocasionado pela produção de ácido acético pelo L. buchneri, o qual permitiu redução nas perdas de matéria seca e manutenção do pH das silagens durante a exposição aeróbia. 
Tabela 3 - Estabilidade aeróbia de silagens de cana-de-açúcar sem aditivo ou contendo Lactobacillus buchneri

\begin{tabular}{lccc}
\hline Item & $\begin{array}{c}\text { Silagem de cana-de-açúcar } \\
\text { sem aditivo }\end{array}$ & $\begin{array}{c}\text { Silagem de cana-de-açúcar } \\
\text { contendo Lactobacillus buchneri }\end{array}$ & $\mathrm{CV}^{1}$ \\
\hline Temperatura máxima, ${ }^{\circ} \mathrm{C}$ & $37,80 \mathrm{a}$ & $22,50 \mathrm{~b}$ & 5,25 \\
Temperatura máxima, horas & $96 \mathrm{a}$ & $120 \mathrm{~b}$ & 3,55 \\
Estabilidade aeróbia, horas & $56 \mathrm{a}$ & $92 \mathrm{~b}$ & 8,82 \\
TA5 $^{2},{ }^{\circ} \mathrm{C}$ & $25 \mathrm{a}$ & $18,2 \mathrm{~b}$ & 15,23 \\
Perda de MS 0-5, \% & $11,10 \mathrm{a}$ & $7,70 \mathrm{~b}$ & 6,56 \\
Perda de MS 5-10, \% & $17,80 \mathrm{a}$ & $9,70 \mathrm{~b}$ & 14,66 \\
Perda média de MS 0-10, \% & $14,45 \mathrm{a}$ & $8,70 \mathrm{~b}$ & 10,60 \\
pH no dia 0 & $3,45 \mathrm{a}$ & $3,52 \mathrm{~b}$ & 0,29 \\
pH no dia 5 & $4,07 \mathrm{a}$ & $3,51 \mathrm{~b}$ & 0,34 \\
pH no dia 10 & $4,30 \mathrm{a}$ & $3,54 \mathrm{~b}$ & 0,77 \\
pH médio 0-10 dias & $3,95 \mathrm{a}$ & $3,52 \mathrm{~b}$ & 0,45 \\
\hline
\end{tabular}

${ }^{1}$ Coeficiente de variação; ${ }^{2}$ Acúmulo da diferença média diária entre a temperatura ambiente e a temperatura das silagens nos primeiros cinco dias de exposição ao ar; a,b Médias seguidas de letras distintas na mesma linha diferem $(P<0,01)$ pelo teste Tukey.

Siqueira et al. (2007) afirmam que silagens de cana-deaçúcar inoculadas com L. buchneri, associadas ou não a outros tipos de aditivos químicos, mantiveram os menores valores de pH. Após cinco dias de exposição aeróbia, esses autores encontraram $\mathrm{pH}$ de 6,1 na silagem sem aditivo e de 3,7 na silagem com Lactobacillus buchneri. Weinberg et al. (2002) relataram que o aumento da estabilidade aeróbia de silagens de trigo e de milho foi ocasionado pela baixa contagem de leveduras, pela reduzida produção de gás carbônico e pelo pH estável durante o período de aerobiose. $\mathrm{O}$ pH médio observado neste estudo durante o ensaio de estabilidade também foi menor $(\mathrm{P}<0,01)$ para a silagem aditivada. Os valores médios de $\mathrm{pH}$ encontrados foram de 3,95 e 3,52 paras a silagem sem aditivo e aditivada, respectivamente. Além de apresentar menor valor médio de $\mathrm{pH}$, a silagem aditivada manteve-se com $\mathrm{pH}$ constante durante todo o período de aerobiose, o que confirma a ausência de microrganismos indesejáveis, em virtude da ação antifúngica do ácido acético.

Não houve diferença $(\mathrm{P}>0,05)$ nos consumos diários de MS, matéria orgânica (MO), FDN, FDA e hemicelulose (Tabela 4) para os componentes avaliados. Não foi observado efeito da inoculação da silagem de cana-de-açúcar, uma vez que os coeficientes de digestibilidade dos nutrientes entre as silagens sem aditivo e aditivada com $L$. buchneri foram semelhantes. Entretanto, houve diferença $(\mathrm{P}<0,05)$ para os coeficientes de digestibilidade da FDN, FDA e hemicelulose entre as silagens e a cana-deaçúcar in natura picada. A cana-de-açúcar apresentou digestibilidade de 49,8; 42,5 e 25,6\% para FDN, FDA e hemicelulose, respectivamente (Tabela 4), enquanto nas silagens foram observados valores médios de $61,2 \%$ de FDN, 55,7\% de FDA e 42,9\% de hemicelulose. Comparando os percentuais médios obtidos para as silagens com os da cana-de-açúcar, observa-se que a ensilagem melhorou a digestibilidade dos compostos fibrosos em 23,0; 31,0; e $67,6 \%$ para FDN, FDA e hemicelulose, respectivamente.

De acordo com Harrison et al. (1989), diversos autores relataram que a inoculação de forragens com bactérias pode melhorar a digestibilidade da silagem produzida. Entretanto, os resultados são controversos. Guim et al. (1995) observaram melhora na digestibilidade aparente da MS e do NDT em silagem de milho inoculada com aditivos microbianos. Por outro lado, Aksu et al. (2006) não observaram diferença na digestibilidade da MS, MO, FDN e FDA de silagens de milho tratadas com aditivos químicos ou microbianos.

O interesse pela ensilagem da cana-de-açúcar é bastante recente. Não existem muitos trabalhos na literatura sobre a digestibilidade aparente no trato digestório total de rações contendo silagens de cana-de-açúcar. Em geral, nos trabalhos encontrados, avaliou-se a digestibilidade in vitro da matéria seca (DIVMS). Pedroso et al. (2007) estudaram a DIVMS de silagens de cana-de-açúcar e não observaram diferença entre as silagens sem inoculante ou tratada com L. buchneri. Silva et al. (2008) observaram redução de $14,25 \%$ na DIVMS quando comparam a canade-açúcar fresca com ensilada durante 85 dias.

Aksu et al. (2004) utilizaram silagem de milho sem aditivo ou aditivada com inoculantes microbianos contendo bactérias homofermentativas e heterofermentativas (L. plantarum, L. brevis, L. buchneri, L. rhamnosus e $P$. pentosaceus) na alimentação de ovinos e observaram que as digestibilidades da matéria seca e da FDN foram maiores na silagem inoculada. Por outro lado, avaliando as características de fermentação, a estabilidade aeróbia e a fermentação ruminal de silagens de milho contendo inoculantes microbianos, Filya (2003) observou que a inoculação com L. buchneri ou L. buchneri mais 
Tabela 4 - Consumo e coeficientes de digestibilidade aparente no trato digestório total (DATT) da matéria seca (MS), matéria orgânica (MO), fibra em detergente neutro (FDN), fibra em detergente ácido (FDA) e da hemicelulose das rações experimentais

\begin{tabular}{lccc}
\hline Item & $\begin{array}{c}\text { Cana-de-açúcar } \\
\text { in natura }\end{array}$ & $\begin{array}{c}\text { Silagem de cana-de-açúcar } \\
\text { sem aditivo }\end{array}$ & $\begin{array}{c}\text { Silagem de cana-de-açúcar } \\
\text { contendo Lactobacillus buchneri }\end{array}$ \\
\hline Consumo, kg/dia & 1,41 & Matéria seca ${ }^{1}$ & 1,64 \\
DATT, \% & 71,1 & 1,45 & 72,1 \\
& & 69,0 & 1,48 \\
Consumo, kg/dia & 1,28 & Matéria orgânica & 73,8 \\
DATT, \% & 72,8 & 1,31 & 0,13 \\
& & 71,0 & 0,74 \\
Consumo, kg/dia & 0,49 & Fibra em detergente neutro & $64,9 \mathrm{~b}$ \\
DATT, \% & $49,8 \mathrm{a}$ & 0,61 & 0,12 \\
& & $57,5 \mathrm{~b}$ & 0,53 \\
Consumo kg/dia & 0,36 & Fibra em detergente ácido & $60,0 \mathrm{~b}$ \\
DATT, \% & $42,5 \mathrm{a}$ & 0,47 & 2,14 \\
& & $51,4 \mathrm{~b}$ & 0,21 \\
Consumo, kg/dia & 0,13 & Hemicelulose & $46,0 \mathrm{~b}$ \\
DATT, \% & $25,6 \mathrm{a}$ & 0,14 & 1,94 \\
\hline
\end{tabular}

${ }^{1}$ Erro-padrão da média.

L. plantarum não afetou a degradabilidade ruminal in situ da MS, MO e da fibra em detergente neutro.

Schmidt et al. (2007) avaliaram o consumo e a digestibilidade de rações contendo 65\% de silagens de cana-de-açúcar aditivadas com inoculantes químicos ou microbianos na alimentação de bovinos e verificaram que os aditivos utilizados (uréia, L. plantarum, benzoato de sódio ou L. buchneri) não foram efetivos em melhorar o consumo e a digestibilidade da matéria seca de silagens de cana-de-açúcar em relação à silagem sem aditivo. Neste trabalho, a digestibilidade da MS foi de 69,0 e 72,1\% (Tabela 4) para as silagens de cana sem aditivo e com Lactobacillus buchneri, respectivamente. Estes valores são superiores aos verificados por Schmidt et al. (2007), que obtiveram valores de 63,4 e 62,5\% para a digestibilidade da MS das silagens controle e inoculada com Lactobacillus buchneri (3,6 x 105/g MV), respectivamente.

$\mathrm{O}$ estudo com aditivos químicos e microbianos, incluindo o L. buchneri, na ensilagem de cana-de-açúcar no Brasil foi iniciado por Pedroso et al. (2005, 2007), que utilizaram a dose de L. buchneri de 3,64 x $10^{5} \mathrm{ufc} / \mathrm{g}$ de matéria natural com base em produto contendo cepas NCIMB40788 (Biotal Ltda, Cardiff, UK).

$\mathrm{Na}$ seqüência dos estudos com $L$. buchneri como potencial controlador da fermentação alcoólica na ensilagem da cana-de-açúcar, a dose de 5,0 x $10^{4}$ ufc/g de massa verde (MV) de forragem foi definida como dose-padrão com base nos estudos realizados por Schmidt et al (2006), que, além da dose mencionada, avaliaram doses de 1 x $10^{5} \mathrm{ufc} / \mathrm{g}$ de matéria natural e 1 x $10^{5}$ ufc/g de matéria natural acrescida com enzimas fibrolíticas, mas não observaram vantagens em doses maiores a 5,0 x $10^{4} \mathrm{ufc} / \mathrm{g} \mathrm{MV}$.

Atualmente no Brasil, o produto comercial LalSil Cana (Lallemand Animal Nutrition) constitui-se na única fonte de Lactobacillus buchneri registrada no Ministério da Agricultura Pecuária e Abastecimento destinada à ensilagem de cana-de-açúcar, sendo recomendada a dose de 5,0 x $10^{4}$ ufc/g de MV. Evidências sugerem que o estudo de doses maiores pode ser intensificado e envolver diferentes variedades de cana-de-açúcar e idades de maturação da planta, além de incluir a exploração de variações regionais e sazonais e de possíveis interações ambientais que possam provocar alterações na população epifítica. É possível obter concentrações ótimas que promovam benefícios também na fase aeróbia.

\section{Conclusões}

A ensilagem da cana-de-açúcar reduz a concentração de carboidratos solúveis ocasionando aumento das concentrações dos compostos fibrosos. Entretanto, rações contendo $50 \%$ de silagem de cana-de-açúcar apresentam melhores coeficientes de digestibilidade aparente da fibra em detergente neutro, fibra em detergente ácido e hemicelulose. A adição do Lactobacillus buchneri melhora a eficiência do processo de ensilagem da cana-deaçúcar, pois reduz as perdas de matéria seca e mantém o pH constante durante o período de aerobiose, promovendo maior estabilidade aeróbia do material ensilado. 


\section{Agradecimento}

À Fundação de Amparo à Pesquisa do Estado de São Paulo (FAPESP), pela concessão da bolsa de estudos ao primeiro autor.

\section{Literatura Citada}

AKSU, T.; BAYTOK, E.; BOLAT, D. Effects of a bacterial silage inoculant on corn silage fermentation and nutrient digestibility. Small Ruminant Research, v.55, p.249-252, 2004.

AKSU, T.; BAYTOK, E.; KARSLI, M.A. et al. Effects of formic acid, molasses and inoculant additives on corn silage composition, organic matter digestibility and microbial protein synthesis in sheep. Small Ruminant Research, v.61, p.2933, 2006.

ALLI, I.; BAKER, B.E.; GARCIA, G. Studies on the fermentation of chopped sugarcane. Animal Feed Science and Technology, v.7, p.411-417, 1982.

CAMPOS, F.P.; NUSSIO, C.M.B.; NUSSIO, L.G. Métodos de análise de alimentos. 1.ed. Piracicaba: Fundação de Estudos Agrários Luiz de Queiroz, 2004. 135p.

DRIEHUIS, F.; OUDE ELFERINK, S.J.W.H.; SPOELSTRA, S.F. Anaerobic lactate degradation in maize silage inoculated with Lactobacillus buchneri inhibits yeast growth and improves aerobic stability. Journal of Applied Microbiology, v.87, p.583-594, 1999.

DRIEHUIS, F.; OUDE ELFERINK, S.J.W.H.; Van WIKSELAAR, P.G. Fermentation characteristics and aerobic stability of grass silage inoculated with Lactobacillus buchneri, with or without homofermentative lactic acid bacteria. Grass and Forage Science, v.56, p.330-343, 2001.

FREITAS, A.W.P.; PEREIRA, J.C.; ROCHA, F.C. et al. Avaliação da qualidade nutricional da silagem de cana-de-açúcar com aditivos microbianos e enriquecida com resíduo da colheita da soja. Revista Brasileira de Zootecnia, v.35, n.1, p.38-47, 2006.

FYLIA, I. The effect of Lactobacillus buchneri and Lactobacillus plantarum on the fermentation, aerobic stability and ruminal degradability of low dry matter corn and sorghum silages. Journal of Dairy Science, v.86, p.3575-3581, 2003.

GUIM, A.; ANDRADE, P.; MALHEIROS, E.B. Efeito de inoculante microbiano sobre o consumo, degradação in situ e digestibilidade aparente de silagens de milho (Zea mays, L.). Revista Brasileira de Zootecnia, v.24, n.6, p.1045-1053, 1995.

HARRISON, J.H.; SODERLUND, S.D.; LONEY, K.A. Effect of inoculation rate of selected strains of latic acid bacteria on fermentation and in vitro digestibility of grass-legume forage. Journal of Dairy Science, v.72, p.2421-2430, 1989.

KLEINSCHIMIT, D.H.; SCHMIDT, R.J.; KUNG JR., L. The effects of various antifungal additives on the fermentation and aerobic stability of corn silage. Journal of Dairy Science, v.88, p.2130-2139, 2005.

KLEINSCHIMIT, D.H.; KUNG JR., L. A meta-analysis of the effects of Lactobacillus buchneri on the fermentation and aerobic stability of corn and grass and small-grain silages. Journal of Dairy Science, v.89, p.4005-4013, 2006.

KUNG JR., L. Preparation of silage water extracts for chemical analyses: standard operating procedure - 001 6.03.96. Worrilow: University of Delaware, Ruminant Nutrition Lab, 1996. p.309.

KUNG JR., L.; ROBINSON, J.R.; RANJT, N.K. et al. Microbial populations, fermentation end-products, and aerobic stability of corn silage treated with ammonia or a propionic acid-based preservative. Journal of Dairy Science, v.83, p.1479-1486, 2000.

McALLISTER, T.A.; FENIUK, R.; MIR, Z. et al. Inoculants for alfalfa silage: effects on anaerobic stability, digestibility and the growth performance of feedlot steers. Livestock Production Science, v.53, n.2, p.171-181, 1998.

MENDES, C.Q.; SUSIN, I.; PIRES, A.V. et al. Desempenho, parâmetros da carcaça e comportamento ingestivo de cordeiros alimentados com cana-de-açúcar ensilada ou in natura. Arquivo Brasileiro de Medicina Veterinária e Zootecnia, v.60, n.3, p.733-740, 2008.

NATIONAL RESEARCH COUNCIL - NRC. Nutrient requirements of sheep. 6.ed. Washington, D.C.: National Academic Press, 1985. 99p.

NUSSIO, L.G.; SCHMIDT, P.; PEDROSO, A.F. Silagem de cana-deaçúcar. In: SIMPÓSIO SOBRE MANEJO DA PASTAGEM: PRODUÇÃO ANIMAL EM PASTAGENS, 20., 2003, Piracicaba. Anais... Piracicaba: Fundação de Estudos Agrários Luiz de Queiroz, 2003. p.187-205.

PEDROSO, A.F.; NUSSIO, L.G.; PAZIANI, S.F. et al. Fermentation and epiphytic microflora dynamics in sugar cane silage. Scientia Agricola, v.62, n.5, p.427-432, 2005.

PEDROSO, A.F.; NUSSIO, L.G.; LOURES, D.R.S. et al. Efeito do tratamento com aditivos químicos e inoculantes bacterianos nas perdas e na qualidade de silagens de cana-de-açúcar. Revista Brasileira de Zootecnia, v.36, n.3, p.558-564, 2007.

RANJIT, N.K.; KUNG JR., L. The effect of Lactobacillus buchneri, Lactobacillus plantarum, or a chemical preservative on the fermentation and aerobic stability of corn silage. Journal of Dairy Science, v.83, p.526-535, 2000.

SANTOS, R.V.; EVANGELISTA, A.R.; PINTO, J.C. et al. Composição química da cana-de-açúcar (Saccharum spp.) e das silagens com diferentes aditivos em duas idades de corte. Ciência e Agrotecnologia, v.30, p.1184-1189, 2006.

STATISTICAL ANALYSIS SYSTEM - SAS. User's guide: statistic. 6.ed. Cary: 1999. 956p.

SCHMIDT, P. Perdas fermentativas na ensilagem, parâmetros digestivos e desempenho de bovinos de corte alimentados com rações contendo silagens de cana-de-açúcar. Piracicaba: Escola Superior de Agricultura "Luiz de Queiroz", 2006. 252p. Tese (Doutorado em Ciência Animal e Pastagens) - Escola Superior de Agricultura "Luiz de Queiroz”, 2006.

SCHMIDT, P.; MARI, L.J.; NUSSIO, L.G. et al. Aditivos químicos e biológicos na ensilagem de cana-de-açúcar. 1. Composição química das silagens, ingestão, digestibilidade e comportamento ingestivo. Revista Brasileira de Zootecnia, v.36, n.5, p.16661675, 2007.

SIQUEIRA, G.R.; REIS, R.A.; SCHOCKEN-ITURRINO, P. et al. Perdas de silagens de cana-de-açúcar tratadas com aditivos químicos e bacterianos. Revista Brasileira de Zootecnia, v.36, n.6, p.2000-2009, 2007.

SILVA, E.J.A.; BORGATTI, L.M.O.; MEYER, P.M. et al. Efeitos do teor de carboidratos solúveis sobre as características da silagem de cana-de-açúcar. Revista Brasileira de Zootecnia, v.37, n.8, p.1375-1382, 2008.

TAYLOR, C.C.; KUNG JR., L. The effect of Lactobacillus buchneri 40788 on the fermentation and aerobic stability of high moisture corn in laboratory silos. Journal of Dairy Science, v.85, p.1526-1532, 2002.

WEINBERG, Z.G.; ASHBELL, G.; HEN, Y. et al. Ensiling wholecrop wheat and corn in large containers with Lactobacillus plantarum and L. buchneri. Journal of Industrial Microbiology \& Biotechnology, v.28, p.7-11, 2002. 